Seção Temática

Debora Breder

Universidade Católica de Petrópolis, Petrópolis, RJ, Brasil

Paloma Coelho

Pontifícia Universidade Católica de Minas Gerais, Belo Horizonte, MG, Brasil

\title{
Desvelando imagens: o visível e o indizível na pele que habitamos
}

Resumo: Este artigo propõe uma reflexão sobre a teia de significados que entretecem a trama de A pele que habito, de Pedro Almodóvar (2011) - significados estes, não raro, contraditórios, que iluminam as zonas de sombra nas quais o pensamento tematiza a diferença. Primeiro, analisa-se o discurso explícito do filme, que versa sobre a plasticidade do corpo e a fluidez do gênero, demonstrando seu caráter construtivo ao se desvincular de categorizações fixas e essencialistas. A seguir, analisa-se o seu discurso implícito, considerando que todo filme, como produto de práticas sociais, é constituído também por um conjunto de ideias que escapam às próprias intenções do autor. Em última instância, trata-se de pensar em que medida o discurso implícito da trama constitui uma espécie de contra discurso em relação ao que o longametragem explicitamente proclama.

Palovras-chave: corpo; gênero; sexualidade; A pele que habito; Pedro Almodóvar.

Au commencement, dans le vide et la nuit, n'existait que le dieu W. Il s'enduisit le crâne de son sperme noir et épais, puis poussa la voûte céleste au-dessus de lui d'un mouvement de haut du corps. Et l'homme créa la femme, Bernard Juillerat

La contrasexualidad afirma que en el principio era el dildo. El dildo antecede al pene. Es el origen del pene. Manifiesto contrasexual, Beatriz Preciado

\section{A pele que habitamos, a pele que nos hablita}

Na epígrafe do roteiro original de $A$ pele que habito vê-se um fragmento de Um sopro de vida, de Clarice Lispector:

\section{(c) (i)}

Esta obra está sob licença Creative Commons. 
Quero a mescla colorida, confusa e misteriosa da natureza. Que se unam vegetais e algas, bactérias, invertebrados, peixes, anfíbios, répteis, aves, mamíferos, até chegar ao homem e seus segredos.

A ideia de mescla, de indefinição e de ambiguidade aludida nesse fragmento constitui o cerne do universo elaborado por Pedro Almodóvar (2011), inspirado na obra Tarântula, de Thierry Jonquet.

A existência dos seres vivos está permeada por duas forças continuamente confrontadas: o caráter contingente, aleatório da natureza; e a racionalidade científica com seus esforços de identificação, classificação e mensuração. Paradoxalmente, a mesma ciência que se empenha em definir e organizar racionalmente os elementos e fenômenos, tornando-os compreensíveis em sua especificidade, também é perpassada por um desejo de, se não sobrepor-se à natureza, ao menos reproduzir sua capacidade de criação. Isso implica, assim, intervenções que subvertem o princípio originário desses elementos, e essa fusão torna mais ambíguas as definições, mais obscuros os limites entre o natural e o artificial.

As intervenções científicas nos corpos proliferam com os avanços das tecnologias, interferindo no curso vital e biológico: os contraceptivos, os métodos de reprodução artificial, os anabolizantes, as cirurgias estéticas... Procedimentos que, cada vez mais, deslocam os limites entre o orgânico e o tecnológico, e tornam fluidas as rígidas demarcações da natureza. Ademais, não são apenas as interferências anatômico-químico-estruturais que agem sobre os indivíduos. Qualquer ser social é permeado por constantes investimentos discursivos em seus corpos ao longo da vida, uma série de mecanismos que os situam e definem a sua experiência a partir de tecnologias também muito precisas, mas que, ao contrário dos procedimentos biotecnológicos, operam mediante esforços para ocultar-se como um artefato. Sendo assim, se torna complexo delimitar o que é essencialmente natural nos indivíduos, considerando que não há experiência anterior aos discursos e práticas sociais por meio dos quais esses corpos se constituem.

O gênero, sendo o primeiro princípio de classificação dos indivíduos, é um dos principais reguladores da experiência por ser o elemento que norteia a posição desses sujeitos na vida social, incidindo sobre os corpos por meio de dispositivos que, como afirma Michel FOUCAULT (1999), os disciplinam e os "normalizam" conforme técnicas de saberpoder, legitimando formulações discursivas como verdades a-históricas e inquestionáveis. Os sujeitos crescem, assim, sendo educados sob uma ideia de "verdade" sobre os corpos, os gêneros, o desejo e a sexualidade e, consequentemente, qualquer divergência nas formas de concepção e vivência dessas categorias é tratada como antinatural, como um "desvio".

O longa-metragem A pele que habito, do cineasta espanhol Pedro Almodóvar (2011), perscruta esse universo, na medida em que interroga o olhar dogmático sobre a constituição de corpos, gêneros e identidades. Aqui a mescla deixa de ser uma transgressão para se apresentar como um processo: o corpo é instável, fluido, plástico, moldável, e não um feito definitivo e imutável da natureza. Conhecido por elaborar histórias que dão vazão aos desejos e às liberdades individuais, em uma espécie de proclamação do direito de ser o que se quer, Almodóvar dessa vez opta por tratar essas questões pelo seu inverso, pela prisão. É pelo aprisionamento do corpo, na sua condição material e simbólica, que o filme acaba por enquadrar as intransigências e (im)possibilidades da liberdade de ação.

No filme, Robert Ledgard é um cirurgião plástico que se dedica a um projeto científico que visa à criação de uma pele artificial imune a qualquer tipo de atrito, como queimaduras ou picada de insetos. Sua esposa, Gal, cujo nome foi dado ao experimento, sofreu um 
acidente de carro que a deixou desfigurada, e Robert não foi capaz de salvá-la. Sua filha, Norma, ao ver a mãe cometer suicídio saltando da janela, desenvolveu um transtorno mental que a afastou do convívio social por muito tempo. Ao sair da clínica em que estava internada, em uma tentativa de ressocialização, Norma vai com o seu pai a uma festa de casamento na qual conhece o jovem Vicente. Apartados do salão de festa, o rapaz, sob o efeito de drogas, inicia com a garota uma conversa dissonante no jardim, sem perceber as suas limitações psicológicas.

Tempos depois, o cirurgião procura sua filha e encontra-a desmaiada, o que o faz pensar que ela tenha sido estuprada. A partir de então, Robert dá início a uma impiedosa vingança, sequestrando Vicente e mantendo-o como cobaia em sua casa. Quando Norma comete suicídio do mesmo modo que a mãe, o médico leva a cabo sua vingança, realizando, sem o consentimento do rapaz, uma cirurgia de mudança de sexo. $O$ filme mostra, gradativamente, as transformações físicas sofridas por Vicente e como isso transforma a sua relação com Robert.

O processo pelo qual Vicente é submetido põe em cena a maleabilidade do corpo, cuja conformação ocorre continuamente, contrariando a sua concepção como uma categoria fixa, rígida e predeterminada, que se esgota em uma suposta condição natural. Ao mesmo tempo, ao evidenciar esse caráter flexível do corpo, o filme sinaliza também a fluidez do gênero e o situa como um aspecto construído constantemente na e pela cultura. Desse modo, tanto o corpo quanto o gênero são retratados como espaços abertos à ressignificação, à reinscrição de suas referências e de seus códigos, transpondo e interrogando as estruturas nas quais se configuram. Conforme nota Judith BUTLER (2002), o anatômico só se apresenta como um "dado" quando atrelado à sua significação, uma cadeia na qual se negocia a diferença sexual, o que faz com que o corpo não possa ser concebido fora de seus termos. O corpo, como um campo inesgotável, só transcende essa condição fixa e predeterminada a partir do momento em que transcende essa significação.

A materialidade, portanto, só adquire sentido quando investida de códigos culturais e formulações discursivas. É por meio dos textos corporais que a identidade e o gênero dos indivíduos são construídos, definidos e informados. O corpo comunica o gênero, na medida em que este último consiste na estilização repetida das ações, o que significa que a estrutura física não é uma superfície passiva e neutra em que a cultura imprime significados, mas ela própria corresponde a um sujeito ativo nesse processo (BUTLER, 2003).

As esculturas da artista Louise Bourgeois, que Vicente, já transformada em Vera, reproduz, remetem à ideia do corpo moldável, plástico. De certa forma, Vera projeta nos bonecos o processo sofrido contra a sua vontade. A própria referência ao trabalho de Bourgeois constitui parte do discurso explícito do filme que, significativamente, é dedicado à artista, conforme declarações do autor (Pedro ALMODÓVAR, 2011). As suas obras, conhecidas pelo caráter ambíguo no tocante à sexualidade - percebido nas esculturas dotadas de ambos os sexos, além de figuras femininas torturadas pela submissão aos rígidos e tradicionais papéis de gênero - também põem em cena as questões que o longametragem enfoca. A reprodução da pintura Mulher Casa (Femme Maison, 1946-1947), que Vera faz na parede de seu quarto - em que aparece o corpo nu de uma mulher, encerrada do pescoço para cima - alude ao sentimento de asfixia, de prisão e cativeiro das mulheres provocado pelas hierarquias de gênero e pela desigualdade de poder.

A mudança de sexo à qual Vicente foi submetido contra a própria vontade, e que implicou uma imposição do gênero feminino, que aos poucos ele, já transformada em Vera, incorpora e performatiza para sobreviver, provoca a reflexão sobre o gênero como representação. Em outras palavras, o revela como performance, denunciando o seu caráter fictício e discursivo. Butler (2003) sublinha, no entanto, que conceber o gênero como 
construção cultural não significa considerá-lo como ilusão ou cópia, o que o relegaria à lógica binária do "real" e do "autêntico". O gênero é (re)definido mediante práticas discursivas contínuas, permeadas por ficções reguladoras que garantem a repetição e a reiteração de atos que são consolidados e cristalizados sob um efeito de autonaturalização bem-sucedida, de maneira que 'isso de 'ser homem' ou 'ser mulher' são questões internamente instáveis" (BUTLER, 2002, p. 186).

Não existe, portanto, um gênero "original", "natural", mas performatividades legitimadas como tais que, ao serem reproduzidas, o desvelam não exatamente como "cópia", mas como uma paródia da ideia do original e do natural. O gênero, desse modo, é uma representação que produz o efeito de autenticidade, cujo êxito depende da transparência com que ele é performatizado, sendo que a impossibilidade de leitura e de interpretação, ou seja, quando os termos do artifício se tornam indistinguíveis, é que a ałuação se fez convincente (BUTLER, 2002; 2003).

A presença cada vez mais intensa da tecnociência na vida social possibilita inúmeras mudanças, atribuindo mais "autenticidade" às formas anatômicas e às performatividades. O limite, porém, é tênue. Qualquer excesso pode resultar no contrário do que se deseja, evidenciando o artifício. É o que se verifica, por exemplo, na rejeição e nas críticas que provocam um procedimento estético malsucedido, quando exposto o exagero ou uma falha cirúrgica. O êxito do autoinvestimento nos corpos depende do quão verdadeiro e natural conseguem parecer as intervenções.

A personagem Vera é a expressão da ideia do cyborg, discutida por Donna HARAWAY (1995), da reinvenção da natureza dos corpos, da desestabilização das fronteiras e da abertura às mesclas. Induz a pensar os organismos como seres portáteis, passíveis de serem fabricados, montados e remodelados, como produtos de uma engenharia tecnológica automatizada. Com efeito, essas criaturas híbridas deslocam as identidades naturalizadas, tornando o próprio gênero uma categoria flutuante. A ambivalência desses organismos desafia a estrutura heteronormativa centrada na visão essencialista do gênero. Em constante mutação, esse "devenir-monstro" reelabora não apenas as tessituras corporais, mas também a linguagem do gênero, do desejo e do prazer.

As imagens de $A$ pele que habito desvelam, pelo tratamento metódico empreendido por Ledgard sobre o corpo de Vicente/Vera, o estatuto contemporâneo do corpo, submetido a intervenções tecnocientíficas. Imagens estas minuciosamente descritas pelo diretor no roteiro; assim, na sequência 131 do roteiro, podemos ler:

\begin{abstract}
O doutor Ledgard the toca os ombros como quem toca um tecido têxtil. No corpo desnudo ainda se percebem as linhas dos diversos retalhos da mesma pele, como remendos de um patchwork epitelial. São sinais visíveis, cicatrizes ainda de cor rosada, que convertem o corpo de Vera (sob o qual palpita Vicente) em um mapa dividido em estados. Os seios têm uma caída perfeita, não parecem alterados pela cirurgia. 0 doutor Ledgard suspende ambos os seios com as mãos. 'Já não parecem de borracha, não é mesmo? [...] As marcas da pele desapareceram. Mas ainda falta trabalho, hein? [...] Te trouxe um body para proteger o seu corpo. Te protegerá, te dará firmeza e te moldará. Acostume-se a usá-lo sempre, como uma segunda pele'. [...] Vicente termina de vestir o body, ainda parece desnudo, mas é uma nudez escultórica, assexuada e robótica (mistura de Diabolik com Fantomas) (ALMODÓVAR, 2012, p. 114-115).
\end{abstract}

A aparência robótica que Almodóvar pretende conferir à personagem remete à figura do cyborg: a referência aos "retalhos" revela, na construção imagética, o caráter maleável da estrutura corporal, sujeita a mutações. A plasticidade do corpo não poderia ser mais bem evocada no comentário de Robert sobre os seios de Vera. 
Ao mesmo tempo, essa engenharia orgânica flexibiliza as noções de "corpo sexuado" e "diferença sexual", abrindo espaço para uma recodificação das políticas do gênero e da sexualidade. Quando Monique WITTIG (2006) declara que as lésbicas não são mulheres porque desviam da função pré-estabelecida para as mulheres em nossa sociedade, ou seja, a reprodução e o casamento heterossexual, é como se as elas fossem programadas para determinados papéis e o fato de transgredir as normas de gênero e da sexualidade, além dos usos dos corpos e da vivência do prazer, representasse uma ressignificação dos sujeitos e de suas práticas. Da mesma forma ocorre com os indivíduos que alteram a conformação dos seus corpos ou subvertem os padrões heteronormativos, borrando os limites de concepções binárias essencialistas e rígidas.

Almodóvar afirma que $A$ pele que habito é uma história sobre vingança. Vicente é submetido a uma mudança de sexo forçada, motivada pela ira de Robert Ledgard pelo suposto estupro de sua filha. Gustavo Martín GARZO (2011), em sua apreciação crítica do filme, comenta que o experimento que o cirurgião realiza com o corpo de Vicente é um dos atos mais sinistros da história do cinema. Obviamente, o procedimento realizado contra a vontade do rapaz constitui uma violência aterradora. Levar em conta, porém, o que representa essa violência, nos permite questionar os fundamentos dessa interpretação. $O$ ato visto como impiedoso é a mudança de sexo forçada de um jovem heterossexual, satisfeito com o seu sexo e com a sua identidade de gênero. Ao ser submetido à transgenitalização contra a sua vontade, ele é compelido não apenas a viver com outro corpo, como também a incorporar um gênero que lhe foi imposto. $O$ título $A$ pele que habito alude a essa ideia: estar aprisionado em um corpo estranho, que não lhe pertence.

De certo modo, o processo ao qual é submetido Vicente ocorre com todos os indivíduos. Nascemos com um sexo que não escolhemos e é a partir dele que nossa identidade é definida e é construída uma série de expectativas sociais, que incluem a imposição de um gênero - o que envolve o aprendizado de maneiras de agir, de se vestir, de falar e de se comportar - e sua correspondência com uma determinada orientação sexual, ou o direcionamento (pré-estabelecido) do desejo. Como sugere Berenice BENTO (2006),

os corpos já nascem operados. Todos estamos já mais ou menos operados(as) por tecnologias sociais precisas. Não existe corpo livre de investimentos discursivos, in natura. O corpo já nasce maculado pela cultura (p. 89).

Assim, a partir do momento em que Vicente se torna Vera, ocorre uma inversão de papéis, na medida em que, se, antes, Vicente era o sujeito que deseja, agora Vera passa a ser objeto de desejo. Isso pode ser observado em algumas cenas, como aquela na qual Vicente tenta seduzir Cristina, a funcionária da loja de roupas de sua mãe, mas ela o rejeita por ser lésbica. Quando retorna à mesma loja, seis anos depois, já como Vera, é ela quem é olhada com desejo por Cristina. Auxiliando sua mãe na loja, Vicente acaricia os seios de um manequim feminino enquanto o arruma na vitrine, assim como toca os seios de Norma antes de abandoná-la desmaiada no jardim. Tempos depois, já transformada em Vera, ela terá os próprios seios apalpados por Robert. Significativamente, há no roteiro a descrição de uma cena, não incluída no filme, na qual, ao sair pela primeira vez, Vera é assediada por homens:

Marília e Vera caminham por uma rua comercial, bastante movimentada. Os anos de reclusão fazem com que Vera se aborreça com a aglomeração e com os espaços abertos. Lhe causa falta de ar. Entre a multidão, os homens the olham com desejo. É uma experiência nova para ela. Há dois homens que a olham e depois fingem não terem olhado. De todo modo, Vera não se sente bem. Respira profundamente. Perde 
estabilidade. Perde a consciência. Marília não tira o olho dela, não sabe se está fingindo. Não confia nela, mas a verdade é que Vera fica pálida por alguns instantes. E caminha de maneira instável. Apoia-se no braço de Marília (ALMODÓVAR, 2012, p. 132).

Embora não tenha sido incluída no filme, esta cena é reveladora para nos dar a noção do que implica essa mudança de sexo do ponto de vista da experiência de Vera em função da vivência de outro gênero e de outro corpo. Como mulher, Vera passa a ser vista como um corpo acessível. Nesse sentido, é emblemático o deslocamento de posição sofrida pela personagem: de suposto estuprador, Vicente, ao se tornar Vera, passa a ocupar o lugar de vítima, sendo estuprada por outro personagem do filme.

\title{
Do visível ao indizível: rasgando a pele
}

O tema da reinvenção da natureza pela ciência já foi explorado pelo cinema diversas vezes, como em Frankenstein (1931), de James Whale, e Os olhos sem rosto (1960), de Georges Franju, duas inspirações de Almodóvar na elaboração do roteiro de A pele que habito.

Um plano do filme condensa imageticamente o poder evocador desse tema. Nele, vemos Robert Ledgard, nosso cirurgião plástico, em ação: inclinado sobre o corpo de Vicente/Vera, que jaz imóvel sobre uma mesa cirúrgica, Dr. Ledgard dá os últimos retoques em sua obra.

O plano não poderia ser mais eloquente, se pensarmos, com Jacques RANCIÈRE (2005), que toda imagem é constituída também pelo não visível, pelo dizível e o indizível, sendo imprescindível considerar a complexa teia de relações que conformam seus múltiplos significados. Do visível ao indizível trata de interrogar de que modo a ordem do mundo aparece, por assim dizer,

\begin{abstract}
'pré-inscrita' na configuração do que pode ser visto e do que pode ser dito, "no fato de que há coisas que podemos ver ou não ver, coisas que escutamos e outras que não ouvimos, coisas que percebemos como ruído e outras que entendemos como discurso" (RANClÈRE In Christine PALMIÉRE, 2002, p. 34 [tradução nossa]).
\end{abstract}

Em $A$ pele que habito, pode-se dizer que um estranho "ruído" percorre a trama, quase inaudível, porém persistente em sua capacidade de arranhar a (suposta) transparência dessas imagens que desfiam - plano após plano, sequência após sequência, de Vicente a Vera - um discurso bem articulado sobre a plasticidade do corpo e a fluidez das identidades de gênero.

Esse "ruído" - ou esse "demasiadamente conhecido que incessantemente se furta" (FOUCAULT, 2008) - é o discurso implícito da trama. Para Foucault, como sabemos, o discurso permanece invisível: ele diz respeito não ao inconsciente do sujeito falante, mas da coisa dita. Nessa perspectiva, analisar o discurso cinematográfico implica considerar, também, a ordem do discurso no cinema; ou seja, tudo o que não é dito explicitamente no desenrolar da trama, mas permanece implícito, sugerido por preterição. É justamente na relação entre o discurso explícito da trama e seu discurso implícito que se pode apreender o "não visível através do visível", segundo expressão de Marc FERRO (1976). São nesses interstícios, nessas zonas de sombra que encobrem o indizível (socialmente) e o dificilmente pensável (simbolicamente), que podemos vislumbrar as fissuras na mise-en-scène do mundo.

O plano não poderia ser mais eloquente, pois, ao enquadrar o Dr. Ledgard em ação, retocando o corpo de Vera, evoca essa evidência sempre turva na tematização simbólica da diferença: a assimetria do corpo sexuado no plano da reprodução, que implica o englobamento do masculino pelo feminino. Inscrita na materialidade do corpo como experiência sensível do mundo, essa assimetria é constituída, nas palavras de Françoise 
HÉRITIER (2000), pelo "privilégio exorbitante que têm as mulheres de engendrar os dois sexos" (p. 34-36), fazendo com que "de uma forma saia outra forma" (p. 34-36), ou seja, que as mulheres - ou melhor, esses corpos falantes que possuem uma "cavidade potencialmente gestacional", segundo expressão de Paul B. PRECIADO (2014b) - sejam capazes de gerar não apenas o idêntico, mas também o diferente. Uma assimetria, não por acaso, tantas vezes obliterada nos mitos, que procuram invertê-la assentando o englobamento do feminino pelo masculino: assim, em inúmeros mitos de origem são os homens que, por um mecanismo qualquer, dão origem às mulheres (Marika MOISSEEFF, 2000; Bernard JUILLERAT, 2000). E o que nos desvela o plano, senão a inversão simbólica dessa assimetria?

Na sequência 138 do roteiro de $A$ pele que habito, podemos ler:

As mãos do doutor Ledgard lhe retiram a máscara asséptica do rosto. Debaixo se revela um belo rosto de mulher, com os cabelos bastante curtos, cresceram cerca de um centímetro. Vicente abre os olhos. Dr. Ledgard: 'Não posso continuar te chamando de Vicente. A partir de agora você se chamará Vera'. O homem batiza a sua obra com um nome que transmite autenticidade (ALMODÓVAR, 2012, p. 118).

Como vemos, trata-se, inequivocamente, de um nascimento: sob as mãos do $\mathrm{Dr}$. Ledgard, Vicente (re)nasce como Vera, "abre os olhos", e é batizada por quem a engendrou.

"O homem batiza a sua obra". O que equivale a dizer, conforme espetacularmente figurado no plano: e o homem criou a mulher... Assim como Deus cria Eva a partir da costela de Adão, Pigmaleão esculpe em marfim Galatea, ou o demiurgo do mito de origem xinguano talha mulheres de pau, nosso cirurgião plástico cria Vera a partir dos enxertos de pele que ele mesmo inventou. A assimetria entre os sexos no plano da reprodução, que implica o englobamento do masculino pelo feminino no processo de gestação, é invertida na miseen-scène social e simbólica do mundo: quantas vezes não vimos assombrados, no cinema, cientistas-demiurgos - esses seres do sexo masculino dotados de extraordinárias faculdades - engendrando o corpo feminino, dando-lhe forma, insuflando-lhe vida?

Do visível ao indizível, parece que a imagem carrega consigo, numa espécie de sobre-impressão, um conjunto de outras imagens que, mesmo integrando diferentes tramas, constituem variações sobre o mesmo tema. Em A linguagem secreta do cinema, JeanClaude CARRIÈRE (1995) notaria, com muita argúcia, que um "filme oculto, feito de milhares de outros, se infiltrou em nossa maneira de olhar as coisas" (p. 195). Nessa teia feita de imagens e de sons - onde encontramos, não raro, o mesmo plano compondo sequências diferentes e, inversamente, as mesmas sequências compostas por diferentes planos -, poderíamos trocar uma imagem por outra, e a eloquência do que "incessantemente se furta" permaneceria a mesma. Senão vejamos: Em Calafrios (Shivers/1975), longa-metragem do cineasta canadense David Cronenberg, deparamo-nos com a mesma cena. O motivo da trama gira em torno de um cientista que, visando ao combate do racionalismo do homem moderno, e estimular sua evanescente libido, cria um parasita e o inocula no corpo de uma jovem mulher. Ao relacionar-se sexualmente com outros parceiros, já infectada, a mulher se torna o vetor de uma epidemia que transforma pacatos cidadãos em pessoas sexualmente incontroláveis.

A trama de Calafrios, como vemos, não poderia ser mais distinta em comparação com a de $A$ pele que habito, assim como a estética do filme, fundada no gore. Realizados por diferentes cineastas, em décadas e países distintos, ambos os filmes, no entanto, por mais díspares que sejam, apresentam praticamente a mesma composição de um plano. Por composição, é escusado dizer, não nos referimos apenas a enquadramentos, ângulos, lentes e filtros, mas, sobretudo, à dimensão simbólica da cena. Em ambas vemos cientistasdemiurgos, habituados a manipular a vida, fabricando corpos femininos... 
Talvez seja porque os cineastas (agentes) nunca sabem completamente o que filmam (fazem), que o que filmam (fazem) faz mais sentido do que sabem, poderíamos dizer, parafraseando Pierre BOURDIEU (2009) em O senso prático...

De fato, como nota Moisseeff (2005), aludindo aos discursos sobre a procriação nas narrativas de ficção-científica - que amiúde retratam a gestação como um processo repugnante, quando não mortífero -, quanto mais a especificidade das faculdades femininas de reprodução é elidida, nas sociedades modernas, mais forte é o alcance desse poder no plano do imaginário. Conforme pondera, a assimetria que o corpo sexuado comporta no plano da reprodução parece difícil de ser pensada no quadro da ideologia moderna, fundada no individualismo e que tem a igualdade como valor central. Ao contrário das sociedades tradicionais de ideologia holista, que procuram inverter essa assimetria mediante uma série de ritos que conferem aos homens a supremacia nesse processo (não necessariamente transcrita, no registro social, como dominação), as sociedades modernas tendem, para promover a igualdade de gênero, a simetrizar o papéis relativos a cada sexo na procriação (do aporte genético à parentalidade, concebidos como sendo igual entre as partes). Assim, para equalizar essa assimetria no que tange à procriação, paradoxalmente, a fecundidade feminina precisa ser rigorosamente controlada, restringida ou retardada ao máximo - quando não expressamente anulada - tornando-se da alçada exclusiva de especialistas.

Se, no princípio, era o dildo, como afirma o Manifesto Contrassexual, instaurando outra imagética, político e poética, em nossa mitologia (pós-humana/pós-orgânica) de origem, é porque o útero continua sendo esse "espaço de exceção", operador simbólico da diferença que precisa ser politicamente eclipsada. "Afirmémosnos como ciudadanas totales, no como úteros reproductivos", propõe Preciado (2014a) no manifesto Huelga de úteros, conclamando à sua descolonização:

De todos os órgãos do corpo, o útero tem sido sem dúvida aquele que historicamente constituiu objeto de maior expropriação política e econômica. Cavidade potencialmente gestacional, o útero não é um órgão privado, mas um espaço biopolítico de exceção ao qual não se aplicam as normas que regulam o resto de nossas cavidades anatômicas. Como espaço de exceção, o útero mais parece com um campo de refugiados ou uma prisão, do que com o fígado ou o pulmão (PRECIADO, 2014a [tradução nossa]).

Não obstante as novas tecnologias de reprodução assistida terem desvinculado não somente sexo e procriação, como também procriação de sexo (Marilyn STRATHERN, 1995), tornando prescindíveis a relação (hetero)sexual e o corpo feminino para a fecundação, o útero continua sendo essa "caixa de Pandora de onde podem sair mil demônios" (MOISSEEFF, 2003), esse órgão de "exceção" expropriado social e politicamente como "laboratório do Estado-Nação" (PRECIADO, 2014). Assim, enquanto assistimos, nos mais diversos campos, ao corpo feminino transformado em arena onde historicamente se trava a luta pela reprodução da sociedade e a hegemonia masculina; vemos, no cinema, corpos deformados em violentas contorções, de onde jorram substâncias viscosas por diversos orifícios, dando à luz predadores horrendos que destroçam o hospedeiro ao nascer. Ou, numa imagética menos alegórica, mas de igual potência simbólica, cientistas-demiurgos insuflando a vida em suas criaturas.

"Hay algo que quieras mejorar? Puedo darme por terminada?", perguntaria Vera ao Dr. Ledgard.

Assim como a saga Alien, analisada por Moisseeff (2005), A pele que habito nos revela, em negativo, uma iniciação feminina, com a personagem Vicente/Vera passando pelas três fases que correspondem aos ritos de passagem: a separação, a margem e a 
agregação. Embora o tempo diegético do filme não as apresente sequencialmente, temos o seguinte encadeamento: retirada de seu ambiente costumeiro, a personagem é apartada da família e dos amigos, sendo isolada em um recinto fechado, sem contato com o mundo exterior. Nesse estado de liminaridade, sem identidade definida, ela passa por uma série de provações que intentam transformá-la, inscrevendo no corpo os contornos de sua nova identidade. Após superar os desafios, a personagem é finalmente reintegrada à sociedade, assumindo seu novo status social. Ela está, por assim dizer, "terminada".

Mas, ao contrário de Alien, não se trata, aqui, de imagens alegóricas: em $A$ pele que habito, o processo de fabricação do corpo e modelamento do feminino retalha, literalmente, a carne. As incisões no corpo vão erigindo paulatinamente, com bisturis, hormônios e outras drogas, uma nova topografia somática que, de Vicente a Vera, delineia uma nova experiência sensível do mundo.

A sensação é constitutiva, parece reiterar cada imagem do filme. Se a materialidade do corpo sexuado só adquire sentido quando investida de códigos culturais e formulações discursivas, é porque essa materialidade é, antes de tudo, experiência sensível do mundo:

Posto que a sensibilidade não é concebível sem o corpo, porque o próprio do corpo é sentir, a percepção que temos das sensações é a percepção que temos do corpo: nosso organismo está no fundamento das representações do mundo e desse "eu" que edificamos permanentemente. A sensibilidade, por conta dos contornos do corpo que sente, delimita consequentemente o mundo tal como o percebemos (Alexandre SURRALLÉS, 2004, p. 67 [tradução nossa]).

Porque o próprio do corpo é sentir que Vicente, ao se tornar Vera, ressente o mundo em seu corpo de outra forma. A primeira lição que lhe ministra o Dr. Ledgard, após a transgenitalização que substitui o pênis pela vagina, é exemplar: "Piensa que tu vida depende de ese orifício. Respiras por él!". A cena não poderia ser mais didática, com o cirurgião retirando de uma maleta vários dilatadores de diferentes tamanhos e enfileirandoos meticulosamente sobre uma mesa, um a um, diante de nossos olhos. A seguir, os dilatadores são enquadrados em primeiro plano: erguem-se como barras de uma prisão através das quais vemos, ao fundo, o rosto aturdido de Vicente.

"Que faço eu de mim?", parece indagar Vicente ao ter que aprender a tornar-se Vera: "No pronome oblíquo, o desdobramento do sujeito em objeto" (NAVARRO-SWAIN, Tania, 2002). Nessa longa aprendizagem para habitar um corpo sexualmente marcado por um novo orifício - "respiras por el" -, a lição derradeira é a que desdobra socialmente o sujeito em objeto: de (suposto) estuprador, Vicente, já na pele de Vera, é estuprada. O sentido metafórico da lição ministrada com os dilatadores não poderia ser mais bem expresso nessa cena que revela, dolorosamente, no deslocamento de posição sofrida pela personagem, a "experiência de um corpo sexuado, cuja pesada materialidade pede um questionamento" (NAVARRO-SWAIN, 2002).

"O estupro é incontornável, mas tabu", diria Virginie Despentes (In Marianne COSTA, 2007) aludindo ao "único evento" em sua vida para o qual não teria encontrado nenhuma "palavra de referência":

Presente em todas as partes, na literatura, na pintura, na vida das mulheres e das nações, como arma de guerra e, no entanto, nunca falamos sobre isso, salvo em debates jurídicos. Ele resume a condição feminina enquanto ameaça indizível à qual devemos ficar submetidas. Somos extremamente numerosas as que fomos estupradas, mas dizer 'sou vítima de estupro', ou mesmo fazer uma ocorrência, continua sendo muito difícil ([tradução nossa]). 
É justamente porque o gênero não é "simplesmente performativo", como lembra Beatriz PRECIADO (2011), sendo "puramente construído e ao mesmo tempo inteiramente orgânico" (p. 21), que o estupro é esse "incontornável" que pode ser infligido por homens e mulheres a mulheres e homens, indiscriminadamente, mas de forma necessariamente assimétrica. Se "pelo ânus, o sistema tradicional de representação sexo/gênero se caga", como proclama o Manifesto contrassexual em seu elogio ao fist-fucking (que permite, dentre outros feitos político-eróticos, que um corpo passível de ser penetrado por um pênis possa penetrar com um punho, subvertendo a relação ativo/passivo implícita na oposição masculino/feminino), é porque o estupro - como prática social e estratégia de guerra (Veena DAS, 1999; Carmen RIAL, 2007; Andréa Carolina PERES, 2011) - continua sendo esse "tabu" que expressa a "brutalidade da violência sexual à qual só o corpo de uma mulher pode ser submetido", como diriam FERNÁNDEZ, Maria Lameira; Maria Victória FERNÁNDEZ e Yolanda CASTRO (2013, p. 150), referindo-se ao romance que inspirou o filme.

O estupro, não por acaso, é fundamental na trama, constituindo o motor da narrativa: enquanto o (suposto) estupro de Norma desencadeia a ação - a vingança do Dr. Ledgard , o estupro de Vera conduz à resolução do conflito. Após ser violada por Zeca, irmão uterino do Dr. Ledgard, Vera é libertada do cativeiro e passa a noite com seu carrasco. Estabelecida então a relação em outros termos, ela finalmente consegue escapar. Ou seja: é o estupro perpetrado por Vicente que o leva ao cativeiro, é o estupro infligido a Vera que a liberta de lá.

Mas isso não é tudo: nesse filme que nos revela, em negativo, um rito de iniciação feminina, o estupro constitui uma metáfora hiperbólica para a primeira relação sexual. "Puedo darme por terminada?", perguntaria Vera ao Dr. Ledgard. Embora o discurso explícito do filme responda que sim na voz do cirurgião, o discurso implícito da trama demonstra que não: após ser literalmente aberta com os dilatadores, Vera precisa ser metaforicamente aberta por um homem para dar-se, de fato, por "terminada". É a relação sexual com um homem que a torna plenamente mulher, conferindo-lhe um novo status na sociedade - a partir de então ela poderá mostrar-se com sua nova roupagem, montada sobre seus saltos e maquiada. Uma cena não poderia figurar melhor o estupro como metáfora para o desvirginamento: no dia seguinte, vemos Vera e Marília, a mãe do Dr. Ledgard, conversando em volta da cama onde ocorreu o evento, em um clima bem intimista, enquanto retiram os lençóis manchados de sangue. Na narrativa, trata-se do sangue de Zeca, assassinado pelo meio irmão ao ser surpreendido estuprando Vera. Um plano mostra os lençóis completamente tingidos de vermelho. Um detalhe que soa tão gratuito quanto mais potente é imageticamente...

Em suma, de Vicente à Vera, o indizível que percorre a trama como um "ruído", arranhando a transparência das imagens em $A$ pele que habito, é essa incontornável materialidade do corpo inscrita, desde sempre, na experiência sensível do mundo. É essa carne compartilhada (Thomas CSORDAS, 2013, p. 293), dotada de afetos e afetada, que torna dificilmente pensável a situação inversa, isto é, uma vingança que operasse a transformação de Vera em Vicente. Porque a "diferença sexual é uma hétero-repartição do corpo na qual não é possível a simetria" (PRECIADO, 201 1, p. 18), que a verdadeira vingança tematizada na trama não é a mudança de sexo forçada, mas o próprio vetor dessa mudança - que na relação hierárquica masculino/feminino, faz do "homem", "mulher".

Essa parece constituir, de fato, a "vingança desmesurada e brutal" que ressoa pelo avesso da trama em cada sequência do filme, o "maior castigo que se pode infligir a um ser humano", como diria o cineasta em uma entrevista, referindo-se ao argumento da trama (ALMODÓVAR In A. LOZANO, 201 1). Pois na "hetero-repartição do corpo" não há, realmente, simetria possível. 
Como nota Preciado (2011), "O processo de criação da diferença sexual é uma operação tecnológica de redução que consiste em separar determinadas partes da totalidade do corpo e isolá-las, transformando-as em significantes sexuais" (p. 18). A construção simbólica da diferença masculino/feminino opera a partir da materialidade do corpo, de suas partes e humores, transformando diferenças anatômicas e fisiológicas em valores: obliteram-se semelhanças, ressaltam-se diferenças, ou vice-versa, marcando sexualmente o corpo a partir de sua função reprodutora, transcrevendo diferença em assimetria e hierarquia (HÉRITIER, 1996).

É justamente essa assimetria que torna dificilmente pensável - nessa trama cujo discurso explícito versa sobre a plasticidade do corpo e a fluidez das identidades de gênero -, a situação inversa, isto é, uma vingança que operasse a transformação de Vera em Vicente. Nesse sentido, não deixa de ser ilustrativo tentarmos imaginar $A$ pele que habito a contrapelo, invertendo o sexo de todas as personagens. Começando, evidentemente, pelo Dr. Ledgard, nosso cirurgião-demiurgo. Assim, teríamos a Dra Ledgard, cirurgiã plástica que, para vingar o (suposto) estupro cometido por Vera contra seu filho adolescente, transforma a jovem em Vicente, substituindo, numa operação de transgenitalização, sua vagina por um pênis. Contudo, ao tentarmos visualizar em detalhes a cena - uma mulher fabricando um corpo masculino - cabe a interrogação: do ponto de vista da potência evocadora das imagens, esta teria a mesma ressonância simbólica que as que constantemente nos descortina o cinema? Afinal, se a mulher já "faz" o homem, produzindo no interior de seu corpo um corpo diferente do seu, qual seria a sua ressonância no plano do imaginário? Para pensar a questão, talvez fosse necessário interrogar quantas vezes vimos, no cinema, cientistas-demiurgas fabricando o corpo masculino, dando-lhe forma, insuflando-Ihe vida... Quanto à Vera, por quais provações teria que passar para aprender a tornar-se Vicente? O estupro, motor maior da trama, também encontraria a mesma ressonância? Embora seja perpetrado e sofrido por homens e mulheres, o estupro, simbólica e socialmente, é declinado no feminino. O silêncio estrondoso que recobre o ato quando a vítima é do sexo masculino - cisgênero e heterossexual - não poderia ser mais contundente: ao "feminizar", o estupro é o maior opróbrio que se pode infligir socialmente a um homem.

\section{Suturas}

Todo filme excede seu conteúdo, sempre. As imagens transbordam da tela, animam o imaginário, se imprimem no mundo. Projetam outros mundos possíveis. Se o filme "vale por aquilo que testemunha", como defende Ferro (1976, p. 06), é porque a mise-en-scène cinematográfica constitui, também, uma mise-en-scène social e simbólica do mundo.

Em A linguagem secreta do cinema, Carrière (1995, p. 195) faria a seguinte observação, aludindo aos detalhes técnicos e narrativos que escapam ao olhar quando vemos um filme; e ao poder de sedução do cinema, que não raro nos faz imaginar ter visto o que não estava em cena: "Tudo o que os realizadores põem nos filmes e que nós não vemos. Tudo o que eles não põem nos filmes, mas que nós vemos".

Deslocada de seu contexto, essa observação nos inspirou na escritura do artigo, pois analisar a relação entre o visível e o invisível, o dizível e o indizível, implica considerar, justamente, tudo o que os realizadores "não põem nos filmes", expressa e conscientemente, mas que nós precisamos ver se quisermos desvelar, na análise do discurso cinematográfico, a ordem do discurso no cinema.

Nesse artigo, procuramos destrinçar alguns fios da complexa teia de significados que entretece $A$ pele que habito, interrogando em que medida o discurso implícito da trama constituiria uma espécie de contradiscurso em relação ao que o filme explicitamente 
proclama. Como vimos, a trama desfia um discurso bem articulado sobre a plasticidade do corpo e a fluidez do gênero, enquanto desvela, pelo avesso, a questão de sua incontornável materialidade inscrita na experiência sensível do mundo. A pele que habito ilumina as zonas de sombra nas quais o pensamento tematiza a diferença, revelando, na potência evocadora de suas imagens, que de Vicente à Vera e de Vera a Vicente, a simetria é impossível.

Para falar sobre o sexo, o gênero e a sexualidade, é preciso começar por um ato de ruptura epistemológica, uma recusa categórica, uma implosão da coluna conceitual permitindo as premissas de uma emancipação cognitiva,

proporia Preciado em Le courage d'être soi: "é preciso abandonar totalmente a linguagem da diferença sexual e da identidade sexual [...]" (PRECIADO, 2014b [tradução nossa]). Se, nas últimas décadas, nas sociedades ocidentais modernas, a linguagem política da identidade sexual vem sendo cada vez mais tensionada, o mesmo, ao que parece, não pode ser dito em relação à linguagem simbólica da diferença sexual, que continua estruturando os mais variados discursos pelos quais pensamos o mundo e as relações que o conformam - e nele nos configuram.

Enquanto não conseguimos abolir a linguagem da diferença sexual para expressar, da pele que habitamos, a nossa experiência sensível do mundo, que, ao menos, a miseen-scène da diferença possa ser imaginada, política e poeticamente, em outros termos.

\section{Referências}

ALMODÓVAR, Pedro. Los archivos de Pedro Almodóvar: el hombre de La Mancha. DUNCAN, P.; PEIRÓ, B. (eds.). Colônia: Taschen, 2011.

BENTO, Berenice. A reinvenção do corpo: sexualidade e gênero na experiência transexual. Rio de Janeiro: Garamond, 2006. 256p.

BOURDIEU, Pierre. O senso prático. Petrópolis: Vozes, 2009.

BUTLER, Judith. Cuerpos que importan: sobre los límites materiales y discursivos del "sexo". Buenos Aires: Paidós, 2002.

Problemas de gênero: feminismo e subversão da identidade. Rio de Janeiro: Civilização Brasileira, 2003.

CARRIÈRE, Jean Claude. A linguagem secreta do cinema. Rio de Janeiro: Nova Fronteira, 1995.

COSTA, Marianne. “Despentes: anarcho-féministe”. Le Magazine Info, 8/06/2007. Disponível em: http://www.lemagazine.info/?Despentes-anarcho-feministe. Acesso em: 03/08/2015.

CSORDAS, Thomas. "Fenomenologia cultural corporeidade: agência, diferença sexual e doença". Educação, v. 36, n. 3, p. 292-305, set./dez. 2013.

DAS, Veena. "Fronteiras, violência e o trabalho do tempo: alguns temas wittgensteinianos". Revista Brasileira de Ciências Sociais, v. 14, n. 40, p. 31-42, jun. 1999.

FANPOP. In "Shivers" (1975) How is the Disease Spread? Disponível em: http://www.fanpop.com/ clubs/horror-movies/quiz/show/455717/shivers-1975-how-disease-spread. Acesso em: 19/ $08 / 2015$.

FERNÁNDEZ, Maria Lameira; FERNÁNDEZ, Maria Victória \& CASTRO, Yolanda. "La piel que habito". InterseXiones, n. 4, p. 145-162, 2013.

FERRO, Marc. "O filme: uma contra-análise da sociedade?". In: LE GOFF, J.; NORA, P. (Org.). História: novos objetos. Rio de Janeiro: Livraria Francisco Alves, 1976.

FOUCAULT, Michel. Arqueologia do saber. Rio de Janeiro: Forense Universitária, 2008 [1969]. . História da sexualidade l: a vontade de saber. Rio de Janeiro: Graal, 1999 [1976].

GARZO, Gustavo Martín. "La verdad del amor". In: DUNCAN, P.; PEIRÓ, B. (Eds.). Los archivos de Pedro Almodóvar: el hombre de La Mancha . Colônia: Taschen, 2011. p. 370-374. 
HARAWAY, Donna. Ciencia, cyborgs y mujeres: la reinvención de la naturaleza. Madrid: Cátedra, 1995.

HÉRITIER, Françoise. Masculin/Féminin. La pensée de la différence. Paris: Éditions Odile Jacob, 1996.

"Articulations et substances". L'Homme, p. 21-38, 2000.

JONQUET, Thierry. Tarântula. Rio de Janeiro: Record, 201 1. p. 160. [Mygale. Paris: Gallimard, 1984].

JUILLERAT, Bernard. "E† l'homme créa la femme. Mythes et non-mythes de Nouvelle-Guinée". In: JAMARD, J-L.; TERRAY, E.; XANTHAKOU. M. (Orgs.). En substances. Textes pour Françoise Héritier. Paris: Fayard, 2000.

LISPECTOR, Clarice. Um sopro de vida - Pulsações. Rio de Janeiro: Nova Fronteira, 1978. p. 162.

LOZANO, A. "Sobre la piel que habito. La piel y de la idea del cambio me ponía ante un universo fascinante". De Verdad Digital, 21/09/2011. Disponível em: http:// www.deverdaddigital.com/pagArticle.php?idA =11673. Acesso em: 08/08/2015.

MINHA VIDA EM FILMES. Os melhores filmes de terror, 2013. Disponível em: http:// minhavidaemfilmes.com/2013/09/. Acesso em: 19/08/2015.

MOISSEEFF, Marika. "Une figure de l'altérité chez les Dentcico". In: JAMARD, J-L.; TERRAY, E.; XANTHAKOU. M. (Orgs.). En substances. Textes pour Françoise Héritier. Paris: Fayard, 2000. "Une femme initiée en vaut... deux: De l'île aux femmes polynésienne à l'Alien américaine". In: BABADZAN, A. (Org.). Insularités. Hommage à Henri Lavondès. Nanterre: Société d'Ethnologie, 2003. p. 79-107.

"La procréation dans les mythes contemporains. Une histoire de science-fiction". Anthropologie et Sociétés, v. 29, n. 2, 2005.

THE ANTI-FILM SCHOOL. The brood, 1979. 2011. Disponível em: https:// antifilmschoolsite.wordpress.com/2012/01/11/the-brood-1979/. Acesso em: 19 ago. 2015.

NAVARRO-SWAIN, Tania. "Identidade nômade: heterotopias de mim". In: RAGO, M. et al. Imagens de Foucault e Deleuze: ressonâncias nietzscheanas. Rio de Janeiro: DP\&A, 2002. p. 325-341.

PALMIÉRI, Christine. “Jacques Rancière: 'Le partage du sensible”. ETC, n. 59, p. 34-40, 2002. Disponível em: http://id.erudit.org/iderudit/9703ac. Acesso em: 14/07/2015.

PERES, Andréa Carolina. "Campos de estupro: as mulheres e a guerra na Bósnia". Cadernos Pagu, n. 37, p. 117-162, julho-dezembro 2011.

PRECIADO, Beatriz. Manifiesto contrasexual. Barcelona: Anagrama, 2011 [2000].

PRECIADO, Paul B. "Huelga de úteros". Números Rojos, 29/01/2014a. Disponível em: http:// blogs.publico.es/numeros-rojos/2014/01/29/huelga-de-uteros/. Acesso em: 23/07/2015.

"Le courage d'être soi". Liberations, 21/11/2014b. Disponível em: http:// www.liberation.fr/chroniques/2014/11/21/le-courage-d-etre-soi_1147950. Acesso em: 23/ 07/2015.

RANCIÈRE, Jacques. A partilha do sensível: estética e política. São Paulo: EXO Experimental/ Editora 34, 2005.

RIAL, Carmen. "Guerra de imagens e imagens da guerra: estupro e sacrifício na Guerra do Iraque". Revista Estudos Feministas, v. 15, n. 1, p. 131-151, janeiro-abril 2007.

STRATHERN, Marilyn. "Necessidade de pais necessidade de mães". Revista Estudos Feministas, Florianópolis, v. 3, n. 2, p. 303-329, 1995.

SURRALLÉS, Alexandre. "Des états d'âme aux états de fait. La perception entre le corps et les affects". In: HÉRITIER, F.; XANTHAKOU, M. (Orgs.). Corps et affects. Paris: Odile Jacob, 2004.

WITTIG, Monique. El pensamiento heterosexual y otros ensayos. Madrid: Editorial Egales, 2006. 


\section{Filmes}

ALIEN, o $8^{\circ}$ passageiro. Direção: Ridley Scott. Roteiro: Dan O'Bannon. EUA, 1979. Gênero: Ficção científica. $117 \mathrm{mn}, 35 \mathrm{~mm}$, cor.

CALAFRIOS. Direção \& roteiro: David Cronenberg. Canadá, 1975. Gênero: Gore. 87mn, 35mm, cor.

FILHOS do Medo, Os. Direção \& Roteiro: David Cronenberg. Canadá, 1979. Gênero: Terror. $91 \mathrm{~m}, 35 \mathrm{~mm}$, cor.

FRANKENSTEIN. Direção: James Whale. Roteiro: Peggy Webling. EUA, 1931. Gênero: Ficção científica. $71 \mathrm{~m}, 35 \mathrm{~mm}$, p\&b.

OLHOS sem rosto, Os. Direção: Georges Franju. Roteiro: Claude Sautet, Pierre Boileau e Pierre Gascar. França, 1960. Gênero: Horror. 88mn, 35mm, p\&b.

PELE que habito, A. Direção: Pedro Almodóvar, Thierry Jonquet. Produtores: Agustín Almodóvar, Pedro Almodóvar. Espanha, 2011. Gênero: Drama/Thriller. 120min.

\section{Quadro}

BURGEOIS, Louise. "Mulher Casa", Femme Maison, Pintura a óleo. Museu Solomon R. Guggenheim, 1946-1947.

[Recebido em 13/02/2017

e aprovado em 30/03/2017]

\section{Unveiling Images: the Visible and the Unspeakable on the Skin We Inhabit}

Abstract: This article proposes a reflection on the web of meanings that intertwine Pedro Almodóvar's The Skin I Live In (2011) plot - these are often contradictory meanings that illuminate the shadow zones in which thought thematizes difference. First, we analyze the explicit discourse of the film, which deals with the plasticity of the body and the fluidity of genre, showing its constructive character when it dissociates itself from fixed and essentialist categorizations. Next, his implicit discourse is analyzed, considering that every film, as a product of social practices, is also constituted by a set of ideas that escape the author's own intentions. Ultimately, it is a matter of thinking to what extent the implicit discourse of the plot constitutes a kind of counter discourse in relation to what the feature film explicitly proclaims.

Keywords: Cinema; Body; Gender; Sexuality; Pedro Almodóvar

Debora Breder (deborabreder@hotmail.com) é doutora em Antropologia pela Universidade Federal Fluminense (UFF/Niterói), com estágio doutoral na École dês Hautes Études em Sciences Sociales (EHESS/Paris). Formada em Cinema pela Escuela Internacional de Cine, Video e Televisión de San António de Los Baños (EICTV/Cuba), é pesquisadora do Grupo de Análises de Políticas e Poéticas Audiovisuais (GRAPPA/UERJ) e professora do Programa de Pós-Graduação em Educação da Universidade Católica de Petrópolis.

Paloma Coelho (palomafcs@gmail.com) é doutora e mestre em Ciências Sociais pela Pontifícia Universidade Católica de Minas Gerais. É especialista em História da Cultura e da Arte pela Universidade Federal de Minas Gerais. Atualmente, se dedica ao estudo do cinema em uma perspectiva sociológica a partir das seguintes temáticas: família, gênero, corpo e sexualidade. É integrante do GRAPPA - Grupo de Análise de Políticas e Poéticas Audiovisuais. 